\title{
A HISTÓRIA E A TESTEMUNHA DE UM MASSACRE COMO ESTRATÉGIAS E TEMAS LITERÁRIOS NO ROMANCE GRÁFICO PETERLOO: WITNESSES TO A MASSACRE (2019)
}

\author{
WITNESSING THE HISTORY OF A MASSACRE AS LITERARY \\ THEME AND STRATEGY IN THE GRAPHIC NOVEL PETERLOO: \\ WITNESSES TO A MASSACRE (2019)
}

ROGÉRIO MIGUEL PUGA*

rogerio_puga@hotmail.com

O presente artigo analisa de que forma o uso da história como narrativa textual e ideológica se assume como uma estratégia e tema literários no romance gráfico realista Peterloo: Witnesses to a Massacre, publicado colectivamente em 2019 pelo historiador Robert Poole, autor do recente estudo Peterloo: The English Uprising (Oxford University Press), também baseado em 400 relatos de testemunhas coevas, e pelos artistas Eva Schlunke e Polyp. Analisamos a forma como o romance é constituído sobretudo por imagens ficcionadas a partir das fontes históricas coevas e por citações desses mesmos documentos que permitem ao leitor criar a ilusão de um contacto mais directo com o passado textualizado e imaginado através das ilustrações, que, por seu turno, funcionam também como narrativas autónomas e alternativas.

Palavras-Chave: romance gráfico histórico; cultura visual; textualização do passado, comics, Massacre de Peterloo.

This article analyses how the use of history, as an ideological and textual narrative, becomes a literary theme and strategy in the realist graphic novel Peterloo: Witnesses to a Massacre, published collectively in 2019 by the historian Robert Poole, author of the recent study Peterloo: The English Uprising (Oxford University Press), also based in 400 contemporary written testimonies, and by the artists Eva Schlunke and Polyp. We also study how the novel mainly consists of images fictionalized from historical sources and quotations of those same historic narratives which allow the reader to create the illusion of direct contact with the textualized past through the illustrations that also function as autonomous and alternative narratives.

Keywords: historical graphic novel; visual culture; textualization of the past; comics; Peterloo Massacre.

DOI: https://doi.org/10.21814/2i.2208

\footnotetext{
* Professor Auxiliar, Universidade Nova de Lisboa, Faculdade de Ciências Sociais e Humanas, Departamento de Línguas, Culturas e Literaturas Modernas, Lisboa, Portugal.
} 
Rulers who neither see nor feel nor know,

But leechlike to their fainting country cling

Till they drop, blind in blood, without a blow. A people starved and stabbed in th' untilled field; An army, whom liberticide and prey

Makes as a two-edged sword to all who wield; ...Are graves from which a glorious Phantom may Burst, to illumine our tempestuous day. — Percy Bysshe Shelley, "England in 1819"

Em 2019 assinalamos o bicentenário do Massacre de Manchester conhecido como Peterloo (16-08-1819), uma efeméride da luta pelos direitos humanos. O presente artigo analisa um relato visual e verbal desse episódio, o romance gráfico ${ }^{1}$ histórico Peterloo: Witnesses to a Massacre (2019), de Eva Schlunke (script editor), Robert Poole (historiador) e Polyp (ilustrador-artista), com investigação adicional de Peter Castre, de forma a estudar como a história do referido episódio é ficcionada e reescrita e se transforma uma estratégia e um tema literários.

Em 1819, apesar de Manchester ser o centro da Revolução Industrial, era também uma das mais conservadoras cidades da Grã-Bretanha. ${ }^{2}$ A urbe não era representada por um Member of Parliament, e apenas uma pequena quantidade de homens abastados votava. A industrialização, o aumento da população e a urbanização transformara a cidade em que os salários eram reduzidos e as condições de vida eram desfavoráveis para grande parte da população, como informa o início do graphic novel. Conquistar o voto seria uma forma de a população mais desprotegida se fazer ouvir e representar, e, antes do massacre de 1819, houve vários protestos sociais no radical North, nomeadamente a Blanket March (1817), que foi desmobilizada pela polícia. Em 16 de Agosto de 1819, os cerca de 60.000 manifestantes que se juntaram pacificamente em St. Peter's Field, entre os quais se encontravam operários fabris e tecelões, exigem o direito ao voto e são atacados pelos militares, a mando das elites política e industrial locais, que tentam, tal como o governo, evitar revoltas. O episódio demorou poucos minutos e foi o mais sangrento na GrãBretanha do século XIX (Poole, 2019, pp. 1-2). Os magistrados observavam a classe

\footnotetext{
${ }^{1}$ Cientes de que o termo 'romance gráfico' não é consensual (Baetens, Frey \& Tabachnick, 2018, p. 1), adaptamos a entusiasmada definição de Stephen Tabachnick (2017, pp. 1-2), no Cambridge Companion to the Graphic Novel: "an extended comic book..., written by adults for adults, and able to tackle complex and sophisticated issues using all of the tools available to the best artists and writers - is the newest literary/artistic genre and one of the most exciting areas of humanistic study today...the graphic novels is truly a form for all seasons [... and] has emerged during the past thirty-five years". Como Moura (2017, p. 16), Zink (1999, pp.1-2), Eisner (2008), Groensteen (2007) e Chute (2017) recordam, a banda desenhada (BD) lida de forma específica com a experiência humana e envolve os leitores de um modo muito próprio, permitindo uma multiplicidade de abordagens e de diálogos culturais. Como Peterloo ilustra, Tabachnick (2017, p. 2) conclui que, numa mesma vinheta, tira ou prancha, "words can do things that visual images cannot - for instance, portray complex inner mental states or complex philosophical meditations — and visual images can do things that words cannot, such as capture subtle facial expressions. An excellent graphic novel combines the best of the verbal and the visual worlds". Recordemos que a BD exige a leitura não apenas de cada vinheta, mas da sequência organizada, pois é da sequencialização (estruturação) e do entrançamento que nasce a interpretação do todo icónico e verbal, rumo ao desenlace da narrativa, que, no caso de Peterloo, o leitor informado já conhece, como acontece, aliás, no romance histórico em geral.

2 Poole (2019, p. 9) recorda que Manchester era a capital da indústria do algodão e a corrupção local generalizara-se nos poderes político e financeiro locais, sem grande interferência do Estado.
}

REVISTA 2i, Vol. 1, N. ${ }^{\circ}$ Especial, 2019, pp. 93-110. eISSN: 2184-7010 
trabalhadora organizada de um apartamento na praça e ordenam o ataque de esquadrões da Cavalaria de Manchester, Salford e Cheshire, que, impreparados e embriagados, carregaram contra mulheres, homens desarmados e crianças, alguns já no chão, e destruíram bandeiras. Alguns militares ficaram presos na multidão e começam a abrir caminho com os seus sabres, ferindo e matando populares. Chegam mais tropas para dispersar a multidão. A primeira vítima, como Peterloo ilustra, é William Fildes (47), com dois anos de idade, que é arrancado dos braços da sua mãe; entre outros mortos, como Margareth Downes, Arthur Neil, Martha Partington, esmagados pela multidão em pânico, entre cerca de 700 feridos, 200 dos quais de ataques com sabres pelas forças policiais. A posição do bebé William Fildes no solo comunica visual e intertextualmente com a famosa foto do bebé sírio refugiado Alan Kurdi (Aylan Shenu) que se afogou na costa de Bodrum (Turquia), em 2 de Setembro de 2015. Essa semelhança universaliza o sofrimento intemporal e a condição de vítimas de abusos, guerras e interesses que assassinam, em prol do lucro. Esse diálogo chama ainda a atenção do leitor para o facto de a actual 'estética do choque' dos mass media normalizar quotidiana e estrategicamente material visual traumático. Em 1819, o governo e os empregadores pretendiam manter o que chamavam 'ordem social', enquanto grupos de reformadores surgem por todo o país, especialmente em cidades industriais. Como recorda Poole (2019, pp. 1-3):

\begin{abstract}
This was not a clumsy exercise in crowd control; it was an atrocity which requires explanation. There was no 'battle of Peterloo' but there was a riot, and it was the forces of order who rioted. They were backed up by the local magistrates, who were backed up in turn by the government...Al this was carried out in plain sight...There was no direct press censorship...Peterloo was the best-documented crowd event of the nineteenth century; over 400 eye-witnesses accounts survive. Many of these were generated by the three major investigations that followed - an inquest, a trial, letters, memoirs, and numerous petitions for justice... Peterloo is often invoked but rarely examined.
\end{abstract}

Os activistas que exigem reforma - nomeadamente o sufrágio universal, a eleição anual para o Parlamento e o fim das corn laws — organizam-se e são associados aos gritos de 'liberdade' da Revolução Francesa, trinta anos depois desse conflito, enfrentando um sistema parlamentar baseado na posse de terras que consideram corrupto e não representativo. O Parlamento teme uma revolução e esse perigo é acentuado por publicações como o Black Dwarf (1407-1819) que advogam: "the ladies are determined at last to speak for themselves... for the soldiers and police officers, they cannot be arrayed against women" (Riding, 2018, p. 78; Poole, 2019, p. 245), no entanto, após o massacre, até o duque de Wellington alerta Lord Sigmouth: "the radicals will impeach you for this, by God they will!" (Poole, 2019, p. 327). Já poetas como Percy B. Shelley publicam críticas a Peterloo através de poemas como "The Mask of Anarchy: Written on the Occasion of the Massacre at Manchester", que termina com as seguintes palavras de exortação à revolta, que, aliás, encerram simbolicamente Peterloo (p. 97):

\footnotetext{
Rise like Lions after slumber

In unvanquishable number!

Shake your chains to earth like dew

Which in sleep had fallen on you:

Ye are many - they are few!
}

Temos assim, ao longo do romance, a representação do protesto como forma de dar voz aos oprimidos e da tentativa violenta de os controlar. A indignação popular após o massacre reforça o Chartism, e contribui para a fundação do semanário Manchester Guardian (05-05-1821), o actual The Guardian (desde 1959), pelo comerciante de algodão John Edward Taylor, que defende os manifestantes como pacíficos e não como 
arruaceiros, como o poder local os caracteriza. Recentemente, Manchester organizou, ao longo de vários anos, a Peterloo Memorial Campaign, que culminou com diversos projectos e actividades em 2019, em que participaram os autores de Peterloo e que possibilitaram a recolha dos cerca de 350 relatos de testemunhas do Massacre, através do Peterloo Witness Project, e a reconstituição, em vídeo, do conflito (http://peterloowitness 1819.weebly.com). O romance gráfico rentabiliza o trabalho de investigação do historiador Robert Poole, cuja história do episódio, que recolhe e analisa os testemunhos coevos sobre o episódio, foi publicada pela Oxford University Press (Peterloo: The English Uprising, 2019) e serve de base para a construção desta nova narrativa visual e instrutiva, como referem os textos que a divulgam na Amazon: "the entire narrative is drawn exclusively from the direct testimony of the time much of it newly unearthed by leading historian Professor Robert Poole, including letters, memoirs, journalist's accounts, spies' reports and courtroom evidence. These have been carefully woven together into rich, vivid illustrations by professional cartoonist, illustrator and graphic novelist Polyp". Os comics já não procuram a legitimação cultural que Heer e Worcester (2009) ainda reclamavam, e actualmente, são cada vez mais os clássicos literários 'transpostos' para ou 'adaptados' como romances gráficos, e essa popularidade, sobretudo entre os leitores mais jovens, foi, decerto, um dos factores para que Peterloo tivesse sido publicado nesse formato, que se ocupa tipicamente também de temas fracturantes e traumáticos. Como conclui Chutte (2017, p. 34),

disaster [as a theme] is foundational to comics... It makes readers aware of limits, and also possibilities for expression in which disaster, or trauma, breaks the boundaries of communication, finding shape in a hybrid medium... With its juxtaposed frames, comics constantly calls readers' attention to what they see, or don't see, and why. What can be seen within the frame - and what can't be seen, or isn't supposed to be seen? Comics is a form about visual presence, a succession of frames, that is stippled with absence, in the framegutter sequence. [It] evokes the unsaid, or inexpressible. Comics highlights the relation between words and images - and therefore addresses itself to the nature of the difficulty of representing extreme situations and experience. What, for example, can be visualized, but cannot be explained in words by a character or narrator? The layers of meaning in handmade images often convey, strikingly, what words alone cannot.

Peterloo foi publicado através de crowdfunding e reinsere, tal como o filme histórico Peterloo (2018), o episódio na cultura visual contemporânea, ao traduzir (Jakobson, 1971) ou transpor (Clüver, 1997, p. 15) intersemioticamente as fontes históricas e a investigação do historiador R. Poole para as ilustrações e para o discurso directo das personagens nas vinhetas. Os balões rectangulares amarelos funcionam como a voz desse historiador que contextualiza a acção, enquanto os balões brancos citam fontes e testemunhos históricos. Já os balões brancos ovais veiculam as falas das personagens históricas e ficcionais. O texto verbal de Peterloo consiste sobretudo em fragmentos de fontes e discursos dos agentes históricos que são transformados em personagens da narrativa visual, servindo as falas para criar a sensação de imediatismo, de testemunho directo e conferir dinamismo à obra. Temos, assim, a transposição de um sistema semiótico verbal para um sistema híbrido (verbal e visual), processo intermedial que Rajewsky (2005, p. 51) classifica como combinação de distintos media num texto e transposição de media, ou seja, "the transformation of a given media product (a text, a film, etc.) or of its substratum into another medium”, no caso, a transposição da investigação de Poole e das fontes para o formato visual do romance gráfico. Como é sabido, os comics, enquanto narrativas mixmedia, justapõem textos pictóricos e verbais e contêm "complex signs in different media that would not reach coherence or self- 
sufficiency outside that context" (Clüver, 1997, p. 8), que, no caso de Peterloo, permitem ao leitor, tal como acontece no romance histórico, ${ }^{3}$ ter acesso à cor local e ao passado (con)textualizados também por imagens realistas. Os autores tentam construir aquilo a que Barthes chama 'efeito do real', e o leitor sabe estar também perante uma performance visual e textualização ficcionais com base em fontes coevas e estudos fidedignos, e daí a sua utilidade pedagógica. Uma versão abreviada de Peterloo é fornecida gratuitamente online a escolas britânicas que a queiram utilizar, pois, como afirma Schwarz (2010, p. 53), a intermedialidade e o romance gráfico são ferramentas didácticas: "students need a new kind of curriculum in the Digital Age, new sites of possibility for learning and creating knowledge. One medium that offers such a site is the graphic novel. The graphic novel can drive current traditional curriculum goals, teach new literacies, offer new topics with which teachers and students can engage, and enable new ways of learning", rentabilizando o diálogo entre a sequência de vinhetas e o texto verbal. O docente poderá ainda tirar partido do facto de o graphic novel ser um locus artístico e literário de tensões e preocupações com a História, o trauma, a memória e a contemporaneidade, como revelam narrativas pessoais de perda, de guerra e de migração forçada, por exemplo, no Irão (Persepolis, de Marjane Satrapi, 2000), as biografias ficcionais históricas (Salazar, agora na hora da sua morte, de J. P. Cotrim e Miguel Rocha, 2006), ou o formato de documentário jornalístico sobre a Guerra da Bósnia (Safe Area Goražde, 2000), o conflito na Palestina (Palestine, ambos do romancista gráfico-‘jornalista político’ Joe Sacco), as cheias em Nova Orleães (A.D.: New Orleans after the Deluge, de Josh Neufeld, 20072008), o 11 de Setembro (In the Shadows of No Towers, de Art Spiegelman, 2004), ou ainda narrativas em que o fantástico e a ficção científica metaforizam caos político ou ambientes distópicos e apocalítpicos (a série manga japonesa Shingeki no Kyojin, conhecida como Attack on Titan, escrita e ilustrada, desde 2009, por Hajime Isayama). A função didáctica deste romance gráfico recorda-nos o título de um capítulo quinto ("The Graphic Novel: Comics Take Themselves Seriously") de Weiner (2012, p. 17) que refere o crescente estatuto dos comics na academia, como também recorda Witek (1989, p. 1) num estudo sobre o romance gráfico histórico que aborda "an event that is 'already told', already weighted with cultural significance" (p. 17), embora esses episódios pretéritos, como Peterloo, possam ser recontados de forma diferente (p. 4), como Cutter e SchlundVials (2018, p. 2) também advogam ao analisar de que forma a História é propositadamente reconfigurada e reconstruída em romances gráficos históricos multiétnicos. Como veremos, os autores de Peterloo desejam acentuar, através da sua (re)escrita gráfica, a importância social da memória do Massacre para, inclusive, analisar, por comparação, o presente.

A representação verbal e visual do tempo e do espaço históricos do confronto de Manchester, bem como a importância do acto de testemunhar e (re)agir perante a violência injusta tornam-se temas e estratégias literárias de Peterloo através do diálogo entre o invisível e o que o romance gráfico torna visível, e entre o dizível e o indizível; daí que Chutte (2016, pp. 1-2) se refira ao graphic novel com uma forma de documentário, de testemunho, e conclua que "accuracy is not the opposite of creative invention", posição e leitura que dialoga com a imagem da capa do romance e com o subtítulo de Peterloo, enquanto o substantivo witness utilizado no plural remete

\footnotetext{
${ }^{3}$ Existem inúmeros romances gráficos com temática histórica, alguns dos quais pensados para a sala de aula, por exemplo: The 9/11 Report (2007), de S. Jacobson e E. Colon; Malcolm X: A Graphic Biography (2008), de A. Helfer e R. DuBurke; Gettysburg: The Graphic Novel (2010), de C. M. Butzer; Evolution: the Story of Life on Earth (2012), de J. Hosler e K. Cannon, The United States Constitution: A Graphic Adaptation (2009), de J. Hennessey e A. McConnell, e World War One: 1914-1918: The War to End All Wars, de A. Sharma.
}

Revista 2i, Vol. 1, N. ${ }^{\circ}$ Especial, 2019, pp. 93-110. elSSN 2184-7010 
simultaneamente para as fontes histórias utilizadas e para os leitores-testemunhas perante essas provas da injustiça. Chutte (2016, pp. 2-5) conclui ainda:

the essential form of comics - its collection of frames - is relevant to its inclination to document. Documentary (as an adjective and a noun) is about the presentation of evidence. In its succession of replete frames, comics calls attention to itself, specifically, as evidence. Comics makes a reader access the unfolding of evidence in the movement of its basic grammar, by aggregating and accumulating frames of information... The forceful emergence of nonfiction comics in its contemporary specificity is based on a response to the shattering global conflict of World War II - and also that we need to see this work as adding to a long history of forms.

Essa aproximação do romance gráfico à figura da testemunha (desenhar para denunciar-presenciar) - característica do chamado comics journalism, sobretudo o do século XXI ${ }^{4}$ - encontra-se logo na capa de Peterloo e informa a auto-classificação da obra e a nossa leitura, como testemunhos visuais e historiográficos de um massacre que deve ser recordado; daí que a autora recorde que a figura da testemunha é recuperada em inúmeros 'romances gráficos documentários'. Peterloo ficciona não a contemporaneidade, apesar de a espelhar metonimicamente, mas sim o passado e a biografia dos não sobreviventes, assumindo-se como um repositório da memória e identidade colectivas de Manchester (rememoração), temática essa que já foi objecto de vários estudos (Iadonisi, 2012; Frey, 2017; Moura, 2017). Braetens e Frey (2015, p. 217) concluem, aliás, que, após o anúncio pós-moderno do 'fim da história', no término do século XX, o passado histórico parece nunca ter sido tão popular, e o romance gráfíco não é excepção, pois a nostalgia (face à ansiedade das crises sociais e financeiras do presente) e a história são temas recorrentes e apresentados de forma inovadora, por exemplo, na obra de Spiegelman, Baker, Clowes, Backderf e Ware. Já Frey (2017, pp. 81-82) recorda que, no romance gráfico das décadas de 70 e 90 do século XX, o passado idealizado é representado como uma nostálgica idade dourada (de sobrevivência e sucesso de 'pessoas comuns' face à adversidade) na qual o terror demonstra a nobreza ética das vítimas, como em A Contract with God (1978), de Will Eisner. No século XXI, e sobretudo através da autobiografia e da reportagem, o graphic novel romance gráfico passa a representar conflitos num passado violento que é revisitado, comentado, criticado e parodiado, tendo aumentado o número de romances documentários-testemunhos e 'metahistoriográficos', como as narrativas mais experimentais anti-guerra de Jacques Tardi (sobre o trauma da Primeira Guerra Mundial), as de Hugo Pratt (série Corto Maltese), Jean Giraud (Moebius), Enki Bilal, Art Spiegelman, Marjane Satrapi, Joe Sacco, Kyle Baker, George A. Walker, Chater Brown, Rakoff, Alan Moore e Eddie Campbell (From Hell, sobre o Estripador), e de Katchor (The Jew of New York), que, tal com Peterloo, utilizam a memória e a testemunha ocular como estratégia narrativa e tema, e recorrem a analepses, prolepses, à fragmentação, à auto-reflexividade (metaficção) e à metahistoriografia, ao pastiche, à ironia, a mitos e lendas, bem como a elementos surreais ou fantásticos, e recusam ou dificultam um pacto absoluto de realismo ou veracidade com o leitor. Por outro lado, alguns romances fundem ficção histórica com outros subgéneros, como pulp horror/crime e comics de super-heróis, transportando alguns desses heróis para contextos históricos específicos, como guerras, ou o Holocausto.

Peterloo rentabiliza, de forma realista e linear, a figura e o estatuto da testemunha ocular da tradição temática do romance gráfico e acentua-a, desde cedo, através da sua própria estrutura, das fontes e da referência ao historiador R. Poole como um dos coautores. Peterloo demonstra, logo nos paratextos, uma postura ideológica e uma

\footnotetext{
${ }^{4}$ Chutte (2016, p. 6) conclui: "Work that is historical and specifically "testamentary" or testimonial is the strongest genre of comics".
} 
interpretação ética, até porque a investigação que sustenta e informa a narrativa foi realizada pelo autor de uma história sobre o Massacre, que, como o nosso estudo demonstrará, dialoga intertexualmente com o romance, ou seja, enquanto ficção histórica, Peterloo é inovador por se basear sobretudo em fontes históricas citadas ipsis verbis que contam a história directamente. $\mathrm{O}$ facto de o testemunho predominante na narrativa ser a palavra colectiva e individual desses documentos torna-se uma estratégia literária interessante, pois dá voz a todas as partes envolvidas no Massacre e coloca o leitor em contacto 'directo' com o passado (a que temos sempre um acesso) textualizado e ilustrado visualmente. O leitor navega entre citações das fontes selecionadas por Poole, a efabulação verbal nas menos numerosas falas das personagens, da autoria de Schlunke, e a ilustração (adaptação-interpretação) desse universo através da arte de Polyp. Os autores utilizam, assim, um medium popular para divulgar um episódio traumático e violento da história da Grã-Bretanha; daí que Polyp apresente expressões faciais sempre tensas ou revoltadas e evite tons claros e alegres, ou seja, a atenção ao detalhe - monumentos, artefactos e objectos culturais, como o vestuário e a comida, paisagens humanizadas, industriais e naturais - e o estilo da narrativa visual veiculam o ambiente social e psicológico representados pelas fontes históricas citadas nos balões, recordando-nos que o referido estilo do desenho no romance gráfico é obviamente relevante. Ao contrário do que acontece, por exemplo, em Nat Turner, de Kyle Baker, sobre a vida do líder revoltoso de escravos, em que o autor optou por quase não utilizar palavras, e as que utilizou são retiradas da narrativa original Confession of Nat Turner para reforçar as suas ilustrações, Peterloo utiliza sobretudo várias fontes históricas e ainda as falas das personagens, enquanto, por exemplo, Written in thew Woods: Three Wordless Graphic Narratives, de George A. Walker, não faz uso de qualquer palavra ao representar visualmente a morte de Tom Thomson, em 1919, os ataques de 11 de Setembro, nos EUA, e a vida de um executivo dos media, Conrad Black, obra sem palavras (explicações) cuja 'leitura' se torna um exercício visual mais exigente.

Peterloo, tal com o outros romances gráficos, justapõe o conteúdo visual a detalhes e informação discursiva veiculada através de paratextos, como, na secção VI, que é constituída por duas partes, a secção das notas finais que explicam factos e episódios históricos presentes em cada página (99-109), com a indicação: "more detail on the material in these notes can be found in Robert Poole's Peterloo", incluindo a foto dos veteranos do Massacre realizada em 1844, por John Birch (p. 109), e a indicação de um site dedicado ao Massacre (peterloo.org). Seguem-se as listas de fontes coevas usadas quase em cada página do romance ("Peterloo: the sources", pp. 110-111) e dos websites sugeridos (p.111), elementos que reforçam o efeito do real e o cariz realista da obra, mas evidenciam sobretudo a investigação científica de Poole que deu origem ao romance que se assume como entretenimento e 'lição' de história. A capa e os paratextos influenciam o horizonte de expectativas do leitor, e a violência policial é, desde logo, o principal tema da capa, uma crueldade exercida de cima para baixo em termos de poder e da posição do polícia em cima do cavalo; no entanto, o olho em que essa actividade é reflectida remete para os testemunhos das fontes históricas utilizadas ao longo do romance e para o próprio estatuto do leitor e da narrativa enquanto testemunhas do Massacre, num processo de mise-en-abyme metaficcional. Essa estratégia é reforçada pelos endorsements na contracapa, de uma jornalista do Financial Times, de um historiador e broadcaster e de três activistas, recordando-nos a denúncia, a actualização do episódio histórico e o paralelismo didáctico do terror pretérito as palavras de José Gil (2004, p. 122) sobre o medo como forma de manipulação, pois "não há um possível quotidiano das sociedades actuais de controlo que não suponha uma forma de microterror". Aliás, a imagem da capa (o olho simultaneamente a testemunhar-observar e a reflectir-denunciar a acção violenta) 
e o subtítulo da obra recordam o leitor que deve ser também testemunha do massacre, enquanto o romance gráfico em geral se assume, como já referimos, também como sentinela na sociedade contemporânea, cada vez mais vigiada e na qual a figura da testemunha (face à necessidade de vigilância social e política) é também mais empoderada, como nos recorda Blocker (2009), ao analisar a forma como o constructo da testemunha é comentado em vária obras de arte através das temáticas do poder, da moral e do estatuto privilegiados dessa mesma figura simbólica que produz e grafa história, com base no que testemunhou e sabe, e que remete, logo desde a capa de Peterloo, para a natureza visual e verbal (testemunhal) do romance gráfico. Aliás, a badana da obra informa: "At a time when democracy is under siege, the memory of Peterloo is all the more vital, and challenges the reader to ask what we have done with the legacy passed on by those who died", palavras que reclamam uma forma diferente de pensar a realidade e de (re)agir, como, aliás, acontece na descrição de vários estudos ingleses sobre $\mathrm{o}$ Massacre. ${ }^{5}$ Peterloo assume-se como uma pluviversalidade de linguagens, media, ideais e leituras que recuperam e 'descolonizam' (em termos de pensamento e de interpretação ideológica) um episódio traumático e simbólico, pois a estética da obra é obviamente ideológica, recordando-nos, como Jill Bennett (2005, pp. 8-9), que "if art is akin to the sensory impression here, then it might be understood, not merely as illustrating or embodying a proposition, but as engendering a manner of thinking. On this account, art is not conceptual in itself but rather an embodiment of sensation that stimulates thought...it is always productive of ideas". A autora invoca também o conceito de empatia crítica e auto-reflexiva como uma forma de nos debruçarmos sobre o imaginário do trauma, recordando que Dominick LaCapra (2014) propõe o conceito de "emphatic unsettlement to describe the aesthetic experience of simultaneously feeling for another and becoming aware of a distinction between one's own perceptions and the experience of the other" (Bennett, p. 8). Este unsettlement poderá, então, ser conseguido pelo romance gráfico enquanto mediador de ideais e valores com que o universo histórico ficcionado é preenchido, ou seja, a arte pode gerar reflexão e empatia no observadorleitor, fenómeno a que que Boltanski (1999) chama 'sofrimento à distância' e a que já Aristóteles chamara catarse. Face aos paratextos que acabámos de citar, pensamos que é também esse um dos objectivo dos autores de Peterloo, como os próprios sugerem na badana, levar o leitor a reflectir sobre geopolítica, opressão e a violência originada pelo abuso de autoridade na Grã-Bretanha do século XIX e na actualidade. Enquanto 'objectos criados' socialmente, os romances gráficos, ao levar os leitores a reflectir, podem funcionar também como instrumentos de agência social (Gell, 1998), concluindo Chute (2016, p. 178), ao abordar a questão da democratização da representação ideológica ou política dos comics, que os graphic novels funcionam como testemunhas visuais metáfora também presente na capa de Peterloo - e mimetizam o (ou são mesmo uma forma de) documentário, "precisely in how it intervenes against the trauma-driven discourse of the unrepresentable and the ineffable".

Em Peterloo, o universo possível histórico é dinamizado através de jogos de cores, tons e sombras, da sensação de movimento de objectos e pessoas que sugerem quer actividades quotidianas de agentes históricos em acção, quer o caos social (pp. 7-14), como acontece na linguagem sequencial fílmica do estilo cinematográfico rentabilizada através das técnicas de editing, close-up e ponto de vista (Christiansen, 2000, p. 112),

\footnotetext{
${ }^{5}$ Na apresentação do estudo de Phythian (2018) lemos, por exemplo, na Amazon: "In a world in which the legitimacy of facts is in constant jeopardy from media and authoritarian bias, the lessons to be learned from the bloodshed and the tyrannical aftermath are as pertinent today as they were 200 years ago. Film director Mike Leigh has defined Peterloo as 'the event that becomes more relevant with every new episode of our crazy times'."
} 
enquanto o uso simultâneo da palavra histórica, da palavra ficcional e da imagem nos recorda, como referem Gaudreault e Marion (2004, p. 65), que cada medium tem a sua "communicational energetics", ou seja, uma forma de explorar, combinar e multiplicar "the familiar materials of expression — rhythm, movement, gesture, music, speech, image, writing" e narrar o enredo à sua maneira. Torna-se, portanto, útil invocar o neologismo mediagenius, um conceito avançado por Marion (1991) para enfatizar o quanto estilo, storytelling e medium são interdependentes (Baetens, 2002, p. 146). Já a maioria dos balões e citações de fontes históricas em caixas rectangulares encontram no interior das vinhetas, servindo alguns desses rectângulos para unir duas vinhetas, sobrepondo-se nas superfícies de ambas e nos espaços intervinhetais para criar uma ideia de continuidadesequencialidade em termos verbais, imagéticos e históricos, sendo, portanto, essas legendas intra-, entra- e inter-imagéticas. A gramática ou sintaxe visual (traço-desenho) e os diálogos entre vinhetas, tiras e pranchas, bem como os vazios entre essas 'molduras' em sequência remetem para diferentes formas de cronologia, linearidade e causalidade e levam Chutte $(2016$, p. 4) a reflectir sobre a noção de história como um 'discurso em aberto', e a considerar que, apesar de Kraus (1999; 2010) defender que a arte contemporânea entrou na sua "post-medium condition", se prestarmos atenção ao romance gráfico, encontramos "a form that is deeply rooted in the specificity of its medium as a source of cultural, aesthetic, and political significance". Peterloo, tal como outras narrativas que já referimos, reclama esse estatuto estético e ideológico desde a capa e assume-se como um memorial às vítimas do massacre em ambos os lados da 'barricada', pois identifica quer o polícia Robert Campbell, de Manchester, que foi espancado, no dia 17 de Agosto, "in revenge attack", quer os quatro cidadãos "believed dead, but whose fate is unknown" (p. 4), havendo, desde cedo, uma migração intermedial das figuras históricas das fontes para o universo ficcional realista (re)criado e disponibilizado em 2019, e no qual os gestos, as palavras e atitudes das personagens pretendem preencher os vazios deixados pelas fontes históricas.

O incipit visual do capítulo primeiro ("Ned Ludd Did It") consiste numa imagem da Manchester industrial de 1819, caracterizada pelo fumo de inúmeras fábricas, sendo, assim, veiculado o ambiente social, ecológico e financeiro da urbe como ponto de partida do texto ideológico que, de seguida, se ocupará do ambiente psicológico dos agentes históricos. Essa primeira vinheta analisa e plasma o complexo espaço da acção de fora, posicionando-se o narrador visual de longe para se distanciar neutralmente dos acontecimentos. Esta estratégia perceptual e visual acentua a sensação e a estética do pitoresco, ainda em voga na altura da acção da obra. O discurso do pitoresco - que começa na segunda metade do século XVIII e atinge o seu auge nas décadas de 80 e 90 - e a sua preocupação pela moldura visual e perceptual, ou seja, pela perspectiva linear do observador que pára para contemplar, iniciam, assim, Peterloo e reforçam a autonomia do sujeito subjectivo que observa a paisagem poluída e manchada ecológica e moralmente através de um ponto de vista único, neste caso urbano, amplo e colectivo. O início do romance adquire, assim, a função de documentário-comentário através da voz impessoal que contextualiza a urbe em que o conflito terá lugar, povoada por uma população trabalhadora (weavers empobrecidos e sem trabalho), ameaçada por um céu escurecido, que se une ao fumo das fábricas, e que vive, de acordo com o poeta Robert Southey, num "hell-hole... all hurry and bustle...dark and airless streets, ... damp air and blackened with smoke and filthy cellars" (p. 7), texto de 1802 citado por Poole $(2019$, p. 27) também na sua história do Massacre. Peterloo adquire assim um cariz neo-realista desde o início, enquanto o campo semântico negativo denuncia o mal-estar social e o contexto propício ao conflito de que a obra se ocupa, ou seja, trata-se de uma versão politizada dos factos, 
pois a história é contada do ponto de vista das vítimas dos privilegiados que poderiam ter escolhido não abusar do seu poder.

Se as caixas rectangulares amarelas de contextualização histórica são as primeiras na obra, seguindo-se os rectângulos brancos que citam fontes históricas, as falas das personagens só aparecem na terceira página da acção (correspondente à p. 9 da obra), o que gera a sensação de uma narrativa mais impessoal e, logo, neutral, e, logo no início da narrativa, encontramos descrições de Manchester da autoria de poetas como Robert Southey, a par das opiniões de "empregadores locais", bem como da voz do historiador, que contextualiza a repressão do governo devido ao medo dos efeitos da Revolução Francesa na Inglaterra e de obras como The Rights of Man (1791), balão informativo que estabelece uma relação intertextual com o 'panfleto' político de Paine e dialoga com a vinheta que exibe um pão espetado numa lança e na qual lemos "Bread or Blood" (p. 8). Aliás, como recorda Poole (2019, p. 8) no seu estudo sobre Peterloo, em meados do século XVIII, o termo-conceito 'democracia', associado à Antiguidade, era conhecido apenas pelos letrados e tinha conotações negativas, pois as democracias eram consideradas instáveis e favoráveis ao despotismo; mas em meados do século XIX o termo já existe no discurso popular, tendo a democracia tido manifestações locais, como a que deu origem a Peterloo. Na página 8 do romance gráfico, exactamente na segunda vinheta, encontramos um edifício em chamas com a legenda que veicula o pensamento do poder londrino e local: "Turbulence...since Jacobinism was infused into the lower orders..., infernal", enquanto outra vinheta convoca a acção dos luditas. Aliás, como Poole (2019, p. 4) recorda no seu estudo, existe uma íntima relação entre os movimentos reformistas em Manchester e em Londres: "if we want to study the national picture, metropolis and cottonopolis have to be conisdered together". 6 A contextualização histórica dos eventos é alargada na página 10, quando o narrador-historiador menciona a explosão do vulcão do monte Tambora, em 1815, a estada do casal Shelley e de Lord Byron no Continente e a redação de Frankenstein (10), personagem sombria associado estrategicamente pelo texto ao monstro social que a revolução industrial criara. Frankenstein é simbolizado visualmente através de um olho (testemunha de opressão), como o da capa de Peterloo, mas rodeado de suturas e ladeado por rodas dentadas industriais, remetendo esses golpes para as feridas sociais e violência infligida num corpo colectivo que também se sente órfão e se revolta. Frankenstein, produzido pouco anos antes do Massacre, é, assim, transformado em símbolo de opressão e num dos intertextos do romance gráfico que informa o leitor que 35.000 soldados regressam das guerras napoleónicas, "glutted English labour markets" (p. 11), ${ }^{7}$ enquanto a imagem correspondente contempla as centenas de milhares de ingleses desaparecidos e mortos nessas guerras, havendo, portanto, dimensões diferentes de um mesmo episódio apresentados nas duas narrativas que compõem o romance, a visual e a verbal. Os desenhos coloridos não se limitam a ilustrar as fontes, mas interpretam-nas e revelam narrativas omitidas de sofrimento, morte, pobreza, e perda que a elite transforma e esbate com histórias de gloriosas vitórias, ou seja, encontramos em Peterloo versões e nuances (leituras) que apenas as imagens 'contam' ou sugerem. Na página 19, encontramos testemunhas femininas a observar, de binóculos, qual voyeuses, as lutas no teatro de Manchester, tal como o leitor-testemunha, que presencia, gradualmente, a formação de grupos de mulheres activistas e a preparação de manifestações e marchas que culminam no "Manchester meeting" (p. 22), que as autoridades tentam anular através de várias estratégias (pp. 26, 30), enquanto a prancha que constitui a página 24 permite ao leitor visualizar e ler o ponto de vista do governo, em Londres, como se de uma partida de xadrez se tratasse.

\footnotetext{
${ }^{6}$ Sobre a actividade dos reformistas em Manchester, veja-se Hargreaves e Hamspon (2018).

${ }^{7}$ Veja-se, também, o estudo de Reid (2018, pp. 1-10).
} 
A mesma metáfora da observação da actividade dos revoltosos através de um binóculo repete-se na página 28 e acentua o estatuto do leitor como testemunha de microconfrontos e do abuso de poder veiculado através do símbolo do sangue das vítimas (pp. $29,51,54,60,62,66-69,71-76)$ derramado até ao dia do Massacre. Desde cedo, e através do jogo de cores e de sombras (claro-escuro), as narrativas visual e verbal de Peterloo informam-nos quer do intenso ímpeto da revolta popular em várias frentes, quer do receio e da repressão por parte da elite local e do governo. As acções nas várias esferas sociais e políticas são apresentadas em simultâneo para veicular os diversos interesses em jogo, desde populares em acção, a privilegiados governantes, juízes e empregadores em reunião, a ecoar palavras de ordem: "fear God; honour the King" (p. 9). A narrativa visual permite, assim, visualizar as fontes escritas, dando-lhes 'vida', enquanto os balões ficcionam os contactos entre as personagens históricas e parafraseiam os arquivos e o estado de espírito dos indignados, a quem o discurso de quem detém o poder chama 'revoltosos'. As imagens da preparação dos manifestantes ordeiros em cada lar individualiza a luta social através dos detalhes do quotidiano (p. 33), enquanto o espaço da acção se volta a abrir para o leitor contemplar o universo rural do Norte de Inglaterra, onde as micro-revoltas se organizam (p. 35), concorrendo a escala maior de pranchas únicas para a sensação de suspense e de dinamismo da acção, ao longo de campos (p. 35), ruas repletas (p. 36), bairros (p. 39) largos (pp. 42, 50-51, 58), no palco dos oradores (pp. 50-51) e no largo durante a dispersão forçada (pp. 58-59), espaços repletos de bandeiras com palavras de ordem como "Equal Representation or Death" (p. 41), "Vote by ballot", "Equality or death", "no corn laws" e "universal suffrage" (pp. 50-51), "Reform" (p. 44), à semelhança das que se ouvem na multidão que se vai assumindo como a personagem (colectiva) mais importante da obra. Esse fluxo de gente permite aos narradores veicular a soundscape, ou paisagem sonora (pp. 37, 39-40, 43-45, 50-51, 53), da revolução, especialmente as palavras de ordem que mulheres e homens gritam ao exigir direitos, justiça social e representatividade política. A focalização do narrador recorda, mais uma vez, o leitor que ele também é testemunha, pois pode observar, através de uma janela em Mount Street, a edilidade local confortavelmente reunida e a decisão dos magistrados (pp. 44-45), a par de uma sucessão de detalhes visuais que transmitem a urgência, o caos e a violência antes do e durante o Massacre (pp. 46-74), muitas vezes do mesmo momento, mas de planos distintos, como acontece nas vinhetas das páginas 48 e 50, nas quais a situação no palco e as bandeiras dialogam intertextualmente com o imaginário da Revolução Francesa, nomeadamente com "A Liberdade Guiando o Povo", de Eugène Delacroix, embora os sabres sejam ainda os dos poderosos opressores. Durante o ataque da polícia, as paisagens visual e acústica veiculam o movimento caótico e a dispersão das pessoas em St. Peter's Field. Uma estratégica bird's-eye view desse campo (pp. 58-59) mostra o cronotópico fluxo da multidão, semelhante a uma corrente marítima, a fugir da morte, enquanto um balão cita Samuel Bamford, que organizou a marcha de Middleton para Manchester e foi posteriormente julgado e condenado: "Then a rush, heavy and resistelss as a headlong sea; and a sound like low thunder, with screams and prayers from the sabre-doomed, who could not escape" (p. 58). Aliás, o relato de Bamford é uma das fontes sobre o massacre mais citadas, tal como o da sua mulher, Jemima Bamford, ambos publicados na autobiografia do primeiro, Passages in the Life of a Radical. Nessa enorme prancha (pp. 58-59), a narrativa visual retoma a primazia, e encontramos apenas esse pequeno balão e cinco pequenas etiquetas com os nomes das vítimas no espaço exacto em que terão falecido. $\mathrm{O}$ exercício cartográfico da morte violenta acentua a sensação de sufoco e o desespero colectivos, bem como a ideia do absurdo das trágicas mortes. $\mathrm{O}$ leitor-espectador assiste ao embate da Cavalaria e dos peões, em St. Peter's Field, enquanto o pó levantado pelo movimento dos cavalos transmite a rapidez e a violência 
do ataque num um espaço aberto de activismo que, de repente, se torna num espaço a fechar e opressivo, de sofrimento e morte, enquanto a multidão é esmagada contra um edifício e foge por vielas e irrompe por janelas de casas na praça para se refugiar (p. 62). Nesse momento da acção, as vinhetas e as pranchas tornam-se maiores, para que a sensação de visionamento e, logo, de testemunho seja acentuada junto do leitorespectador, que vê-testemunha com mais detalhe e maior amplitude através desses grandes planos que marcam momentos de tensão, como se de fotografias se tratasse (pp. 41-67), individualizando as vítimas com vinhetas dedicadas a cada uma delas através da técnica do zoom in, no exacto momento da morte violenta, em que, por exemplo, Mary Heyes é espezinhada e vista morta no chão, e John Ashton é esmagado por cavalos policiais (p. 60). São ainda ilustrados testemunhos pessoais e jornalísticos sobre os acontecimentos desse dia (pp. 62-67) e que descrevem como a população contra-ataca a polícia (p. 68) ao ser agredida, sobretudo através das imagens violentas de sangue e de corpos deformados pelos cortes de sabres na página 72 , ou do sangue que permanece na relva do largo (p. 74), a par das roupas que as vítimas deixaram para trás (p. 73), enquanto se tratam feridas profundas na enfermaria (pp. 76-77). Na segunda vinheta da página 70 lemos ainda um testemunho sobre um dos polícias que defende os civis indefesos de um seu colega, que os atacava. As 'molduras' que representam o Massacre, nomeadamente os ataques policiais, as reacções e os gestos dos populares em St. Peter's Field ecoam intertextualmente as representações pictóricas coevas, nomeadamente as mães com bebés nos braços, os civis feridos e o ataque indiscriminado dos polícias, por exemplo, na gravura do Massacre publicada por Richard Carlile (01-10-1819), em "The Massacre of Peterloo, or Britons Strike Home", de George Cruikshank, ou em "The Massacre of Peterloo! or a Specimen of English Liberty", de J. L. Marks, todas disponíveis online, tendo surgido também dezenas de poemas e cantigas sobre o Massacre após o mesmo (Morgan, 2019). Na página 71 de Peterloo é novamente recuperada a temática do testemunho ocular através da imagem de um olho, semelhante ao da capa, em que encontramos reflectido um polícia a agredir mulheres, funcionando o rectângulotestemunho do jornal Leeds Mercury como uma denúncia jornalística: "Defenceless women seemed more particularly the object against which their hostility was directed" (p. 71); daí o retomar da metáfora (visual) da testemunha ocular e da importância do jornalismo e da nossa memória actual. Assistimos ainda a um residente e agente histórico a insurgir-se e a comparar logo este ataque à violenta batalha de Waterloo (p. 73), aproximação que daria ao episódio a designação Peterloo. Já o capítulo quarto, intitulado "I understand I have a right to tell all I saw", recupera a temática da testemunha que denuncia as revoltas pontuais contra a polícia, as prisões de revoltosos por traição, os inquéritos às mortes, as acusações e penas de alguns revoltosos e do staff do Manchester Observer, bem como a tentativa, por parte das autoridades, de fazer esquecer o conflito e de controlar a população ao publicar nova legislação "to prevent further mass protest and to restrict 'seditious' publications", leis essas que são listadas pelo narrador (p. 90). O capítulo enfatiza a importância da imprensa local para a denúncia do ataque à população através do surgimento do novo jornal "liberal", o Manchester Guardian, ou seja, a existência de mais uma testemunha incómoda, que, aliás, daria origem ao actual The Guardian, tido por muitos leitores como o jornal de referência europeu.

A primeira vinheta da página 90 ilustra o controlo social exercido pelos poderes económicos e políticos através da imagem comum do cadeado a fechar a boca de oprimidos (ausência de liberdade de expressão), metáfora visual utilizada também pelas sufragistas e por anti-feministas nos séculos XIX e XX num cartaz, fonte histórica visual que é também utilizada na página 96 para estabelecer um paralelismo entre as exigências dos activistas de Peterloo, entre os quais se encontravam inúmeras mulheres, e a luta de 
feministas, como Mary Wollstonecraft, mãe de Mary Shelley, referida estrategicamente logo no início do romance gráfico. Aliás, no seu estudo sobre o Massacre - que, tal como o romance, se centra em três factores para além da revolução industrial, a política, a Manchester empobrecida e a guerra contra França - Poole (2019, p. 5), recorda:

the involvement of female reformers...turns out to be central to events; misogyny and male honour were important factors in the attack on the crowd, not to mention an almost colonial brand of arrogance, picked up part in Ireland. The way that the marchers organized themselves in procession tells us a lot about how they saw their place in the political order, how they imagined it could be changed, and why the authorities feared them.

Na página 91, o narrador-historiador informa ainda que, na Itália, Percy Shelley toma conhecimento do Massacre e redige o poema "The Masque of Anarchy", mais um intertexto de Peterloo. O enredo principal termina com uma imagem e citação de Henry Hunt, que cumpre uma pena de 16 meses na prisão de Ilchester, e outra imagem de uma manifestação nocturna, em 16 de Agosto de 1820, para assinalar o primeiro aniversário do Massacre. O derradeiro quinto capítulo ("Every government rests ultimately on force") consiste em três pranchas com informações sobre o destino dos agentes históricos Henry Hunt, que, em 1830, seria eleito M.P. por Preston, e Samuel Bamford, sobre a Chartist Campaign de 1838-1839, que retoma e estende as exigências dos massacrados de Peterloo, sobre o desenvolvimento de Manchester nos anos 30 e 40, e os Great Reform Acts de 1832, 1867 e 1884, que alargariam o direito ao voto, tornando claro que as conquistas sociais são normalmente lentas e exigem medidas drásticas e até derrotas, como o Massacre, pois só assim se 'abalam' regimes opressivos e se dá início à cadeia de mudanças progressivas. As últimas vinhetas e balões-legendas do capítulo V elencam os memoriais e placas comemorativas que se foram erguendo no Reino Unido em homenagem aos revoltosos em 1842, 1972 e 2019, trazendo as comemorações e as homenagens das vítimas do conflito até à contemporaneidade, pelo que a última vinheta da obra mostra a actual praça onde se deu o Massacre e cita uma campanha actual de activistas locais para as comemorações do Massacre, a Peterloo Memorial Campaign: "Peterloo isn't just about the past: it's about the present, and the future as well. Its memory throws a challenging question at us all: what have we done to defend, nurture and spread the democratic legacy that these people died to pass on to us?" (p. 97) As últimas palavras da obra são do poeta Shelley, que redigiu o já citado poema "The Masque of Anarchy", a propósito de Peterloo. Simbolicamente, o casal Shelley, conhecido como activista de várias causas sociais, confere circularidade temática à obra ao aparecer antes da acção referência à publicação de Frankenstein como fruto da opressão da Inglaterra industrial (p. 10), à redacção do poema "The Masque of Anarchy" (p. 91) logo após o Massacre, texto esse que encerra Peterloo (p. 97) e influenciaria Henry David Thoreau, Mahatma Gandhi e Pauline Newman, entre outros activistas - e no excipit da obra, ao simbolizar os ecos literários, sociais e visuais que perduram sobre Peterloo. A referência à luta dos Shelley universaliza e intemporaliza estrategicamente a defesa dos direitos humanos, inclusive a actual, tal como sugerem as legendas da derradeira vinheta, que actualiza essa luta e questiona o leitor.

Como verificámos ao longo deste estudo, Peterloo enfatiza o carácter ordeiro dos manifestantes, o envolvimento activo das mulheres e o abuso de poder por parte da elite de Manchester, que se opõe, tal como o governo, às mudanças sociais que melhorariam a qualidade de vida da população. Aliás, um dos autores do romance, o historiador R. Poole (2019, p. 4), conclui, no seu estudo: "if Peterloo really was a massacre then the weight of explanation must fall on the perpetrators rather than on the victims", assumindo-se essa sua história do massacre e o romance gráfico como history from below e narrativas 
ideológicas que reflectem sobre o passado e as memórias que dele podemos produzir e manter e questionam, portanto, a representação historiográfica e as suas (re)interpretações. Como vimos, Peterloo levanta ainda outras questões interessantes relacionadas com a transposição intermedial de relatos históricos orais e escritos para o formato visual (romance gráfico), com a tentativa de atribuir existência visual a personagens históricas de que não há registos pictóricos, e com a utilização de medium e género literário (agente cultural e ideológico) popular para informar um público cada vez mais alargado sobre questões históricas e de direitos humanos. Peterloo ficciona paisagens, figuras e acontecimentos pretéritos traumáticos, e fá-lo com base em fontes e no 'efeito do real', que, como sabemos, influencia o horizonte de expectativas do leitor. A história e a historiografia tornam-se, assim, simultaneamente estratégias e temáticas literárias, bem como de debate ao longo do romance gráfico que se assume como um memorial que assinala e reintroduz Peterloo na cultura visual inglesa, homenageando as vítimas que lutaram pela justiça social e pelos direitos humanos, conquistas recentes e incompletas da história da humanidade, que exigem manutenção e que nunca deveremos tomar por garantidas; aliás, como conclui Moura (2017, p. 14), ecoando (Fawaz, 2016):

comics are part and parcel of all modern human's artistic expressions. As such, they participate in the artefactuality and social agency of other disciplines. Comics not only may reflect the principles of a certain society as they may act upon them and propose alternative configurations... As a historically and socially determined cultural and aesthetic production, comics are at one time guided by the strong personality and creativity of its individuated authors but also fully integrated in specific economic, technological and political conditions, which includes both the conditions of production and of reception. They are then as able to respond to the world as any other human endeavour. They contribute, either through imaginative fiction or critical assessment, to the discussion and rethinking of a given society's mores and politics. Moreover, and especially so, they provide very often story worlds that may help one to imagine alternative spaces, identities and practices...comics may respond to certain issues, including to the very conditions that may lead totraumatogenic situations in the contemporary world.

Peterloo sugere, desde a imagem na capa aos endorsements da contracapa, que é necessário que esses testemunhos perdurem e sirvam de modelos e(sté)ticos para reflexão a propósito de actos violentos como o Massacre de Manchester, pois o "cultural engagement" é, como já acontecia na época do Romantismo, uma forma de resistência e resiliência (Demon \& Hewitt, 2019). O romance gráfico histórico ou documentário assume-se, portanto, como uma nova forma de arte simultaneamente popular e 'erudita', como testemunha e comentário realistas do passado e da contemporaneidade, e, se Babic (2014) e Cutter e Schlund-Vials (2018) ${ }^{8}$ estudam a forma como os graphic novels históricos podem rever a história 'oficial', Polak (2017, p. 11) demonstra de que forma o ponto de vista do oprimido (desde a 'sarjeta' metafórica) é utilizado propositadamente em metaficções historio/gráficas (historio-metagraphics) para estimular "ethical engagement" e questionar — tal como o romance histórico modernista e pós-moderno de que forma o passado é representado, evidenciando "[that the] reader's awareness of the graphic narrative as something produced is embedded in the form", por exemplo

\footnotetext{
${ }^{8}$ Cutter e Schlund-Vials (2018, pp. 2, 6, 15-16) recordam-nos que: "using the open and flexible space of the graphic narrative page - in which readers can move not only forward but also backward, upward, downward, and in several other directions - contemporary multiethnic writers present history as a site of struggle where new configurations of the past can be manipulated and alternate conceptualizations of present and future histories may be envisioned...History is undeniably textualized and textual...polyvocal, intertextual, and metatextual, mediated through the act of "redrawing...flexible constructions of the past...History...still continues to matter as a space to reclaim the past... introducing a sense of history as multivocal, unstable, slippery, and always mediated by human consciousness".
} 
através de obras como Deogratias, de J. P. Stassen (um relato fragmentado e não-linear sobre as consequências do genocídio do Ruanda), Watchmen, de A. Moore e D. Gibbon, Scalped, de J. Aaron e R. M. Guera (sobre os ataques a nativos norte-americanos na Reserva de Pine Ridge), Bayou, de J. Love (que ecoa ficcionalmente o assassinato de Emmett Till), e uma edição de Hellblazer, de M. Carey e M. Frusin sobre o massacre de aborígenes da Tasmânia. Tal como os autores de Peterloo, também os desses romances gráficos históricos utilizam a focalização e o ponto para desestabilizar ou questionar a posição ética do leitor e repensar a tarefa de (re)escrita e a importância da leitura da história regional, que obras como as que analisámos voltam a transportar para a esfera (inter)nacional, como o poema de Shelley fez logo após Peterloo. O facto de o romance gráfico se ter tornado uma forma cultural reconhecida e popular permite-lhe reagir ao celebrar efemérides históricas (Frey, 2017, p. 92) que interpreta e divulga, como acontece com Peterloo, e pode, inclusive, apresentar e contrapor as várias verdades historiográficas que encontramos se olharmos atentamente para documentos oficiais ou para (auto)biografias, testemunhos e textos jornalísticos, todas elas narrativas que importa continuar a interrogar com espírito crítico. Os narradores parecem fazer isso mesmo ao desafiar os leitores a regressar ao Massacre para criar uma noção 'instável' do passado que lhes permita analisar e indagar criticamente o presente através das complexas e multimodais versões do cada vez mais conhecido conflito de Manchester.

\section{REFERÊNCIAS}

Babic, A. A. (2014). Comics as History, Comics as Literature. Madison: Fairleigh Dickinson University Press.

Baetens, J. (2002). Revealing traces. A new theory of graphic enunciation. In R. Varnum \& C. T. Gibbons (eds), The language of Comics: Word and image (pp.145-155). Mississippi: Univeristy Press of Mississipi.

Baetens, J. \& Frey, H. (2015). The Graphic Novel: An introduction. Cambridge: Cambridge University Press.

Baetens, J., Frey H. \& Tabachnick, S. E. (2018). Introduction. In J. Baetens, H. Frey, \& S. E. Tabachnick (eds), The Cambridge history of the Graphic Novel (pp.1-18). Cambridge: Cambridge University Press.

Bennett, J. (2005). Empathic vision: Affect, trauma, and contemporary art. Stanford: Stanford University Press.

Blocker, J. (2009). Seeing witness: Visuality and the ethics of testimony. Minneapolis: University of Minnesota Press.

Boltanski, L. (1999). Distance suffering: Morality, media and politics. Cambridge: Cambridge University Press.

Christiansen, H.-C. (2000). Comics and Films: A narrative perspective. In A. Magnussen \& H.Ch Christiansen (eds), Comics and culture (pp.107-121). Copenhaga: Museum Tusculanum Press. 
Clüver, C. (1997). Estudos Interartes: Conceitos, termos, objetivos. Literatura e sociedade, 2, 37 55.

Chute, H. (2017). Why Comics? From underground to everywhere. Nova Iorque: Harper Collins.

Cutter, M. J. \& Schlund-Vials, C. J. (2018). Redrawing the historical past: History, memory, and multiethnic Graphic Novels. Athens: University of Georgia Press.

Davies, P. F. (2019). Comics as communication: A functional approach. Londres: Palgrave.

Demson, M. e Hwitt, R. (Eds.) (2019). Commemorating Peterloo: Violence, resilience and claimmaking during the Romantic Era. Edinburgo: Edinburgh University Press.

Earle, H. E. H. (2019). Comics, trauma, and the new Art of War. Jackson: University Press of Mississippi.

Eisner, W. (2008). Comics and Sequential Art. Nova Iorque: WW Norton.

Eisner, W. (2008). Graphic storytelling and visual narrative. Nova Iorque: W. W. Norton.

Fawaz, R. (2016). The new mutants: Superheroes and the radical imagination of american Comics. Nova Iorque: New York University Press.

Fresnault-Deruelle, P. (1976). Du Linéaire au tabulaire. Communications 24: La Bande Dessinée et son Discours, 7-23.

Fresnault-Deruelle, P. (2008). Images à mis-mots: Bandes Dessinées, Dessins d'humour. Impressions Nouvelles: Bruxelas.

Frey, H. (2017). Historical Fiction. In S. E. Tabachnick (ed), The Cambridge companion to the Graphic Novel (pp. 80-96). Cambridge: Cambridge University Press.

Gaudreault, A. \& Marion, P. (2004). Transécriture and narrative mediatics: The stakes of Intermediality. In R. Stam \& A. Raengo (eds), A companion to Literature and Film (pp.5870). Oxford: Blackwell.

Gell, A. (1998). Art and agency: An anthropological theory. Oxford: Oxford University Press.

Gil, J. (2004). Portugal, hoje: O medo de existir. Lisboa: Relógio d'Água.

Gordon, I., Jancovich, M. \& McAllister, M. P. (Eds). (2007). Introduction: Film and Comic Books. Jackson: University Press of Mississippi.

Groensteen, T. (2007). The system of Comics. Jackson: The University Press of Mississippi

Hargreaves, R. \& Hampson, A. (2018). Beyond Peterloo: Elijah Dixon and Manchester's forgotten reformers. Filadélfia: Pen \& Sword History.

Hatfield, C. (2005). Alternative Comics: An emerging literature. Jackson: University Press of Mississippi.

Hatfield, C. (2009). The art of tensions. In J. Heer e K. Worcester (eds), A Comics studies reader (pp.132-148). Jackson: University Press of Mississippi. 
Heer, J. \& Worcester, K. (2009). A Comic studies reader. Jackson: The University Press of Mississippi.

Iadonisi, R. (Ed) (2012). Graphic history: Essays on Graphic Novels and/as History: Newcastle upon Tyne: Cambridge Scholars Publishing.

Jakobson, R. (1971). Selected writings: Word and language 2. Haia: Mounton.

Krauss, R. (1999). "A voyage on the North Sea": Art in the age of the post-medium condition. Londres: Thames and Hudson.

Krauss, R. (2010). Perpetual inventory. Cambridge: MIT Press.

LaCapra, D. (2014). Writing History, Writing trauma. Baltimore: John Hopkins University Press.

Marion, P. (1991). Traces en cases. Lovaina: Universidade Católica de Lovaina.

McCloud, S. (2006). Making Comics: Storytelling secrets of Comics, Manga and Graphic Novels. Nova Iorque: Harper Perennial.

Morgan, A. (2019). Ballads and songs of Peterloo. Manchester: Manchester University Press.

Moura, P. D. V. (2008). Memória da Banda Desenhada: Presença e leituras da memória em sete casos da Banda Desenhada contemporânea francófona. Dissertação de Mestrado, Universidade Nova de Lisboa, Lisboa.

Moura, P. D. V. (2017). Small panels for lower ranges: An interdisciplinary approach to contemporary Portuguese Comics and trauma. Tese de Doutoramento, Faculdade de Letras da Universidade de Lisboa, Lisboa.

Polak, K. (2017). Ethics in the gutter: Empathy and historical fiction in Comics. Columbus: Ohio State University Press.

Poole, R. (2019). Peterloo massacre: The English uprising. Oxford: Oxford University Press.

Phythian, G. (2018). Peterloo: Voices, sabres and silence. Stroud: The History Press.

Refaie, E. (2003). Understanding visual metaphor: The example of newspaper cartoons. Visual Communication, 2, 75-95.

Rajewsky, I. O. (2005). Intermediality, intertextuality, and remediation: A literary perspective on Intermediality. Intermédialités: Histoire et théorie des Arts, des Lettres et des Techniques/Intermedialities: History and theory of the Arts, Literature and Techniques, 6, 43-64.

Read, D. (1958). Peterloo: The 'Massacre' and its background. Manchester: Manchester University Press.

Reid, E. (2018). The Peterloo Massacre. Londres: Windmill Books.

Riding, J. (2018). The story of the Manchester Massacre of Peterloo. Londres: Head of Zeus.

Schwarz, G. (2010). Graphic Novels: New sites of possibility in the secondary curriculum. In B. S. S. \& D. J. Flinders (eds), Curriculum and Teaching Dialogue 12:1-2 (pp.53-66). Charlotte: Information Age Publishing. 
110 | ROGÉRIO MIGUEL PUGA

Tabachnick, S. E. (2017). Introduction. In S. E. Tabachnick (ed), The Cambridge Companion to the Graphic Novel (pp.1-7). Cambridge: Cambridge University Press.

Weiner, S. (2012). Faster than a speeding bullet: The rise of the Graphic Novel. Nova Iorque: NBM.

Williams, P. (2020). Dreaming the Graphic Novel: The novelization of Comics. New Brunswick: Rutgers University Press.

Witek, J. (1989). Comic Books as History. Jackson: University Press of Mississippi

Zink, R. (1999). Literatura gráfica? Banda Desenhada portuguesa contemporânea. Oeiras: Celta Editora.

(O autor segue a antiga ortografia.) 